\title{
INFLUÊNCIA DO TRATAMENTO OSMÓTICO NA PRODUÇÃO DE TOMATE DESIDRATADO
}

\section{INFLUENCE OF OSMOTIC TREATMENT IN PRODUCTION OF DEHYDRATED TOMATO}

\author{
Mary de Fátima Dias Queji ${ }^{1}$, Lauren Sabim Pessoa ${ }^{2}$ \\ ${ }^{1,2}$ Universidade Estadual de Ponta Grossa - UEPG - Ponta Grossa - Brasil \\ melqueji@hotmail.com; nini_sabim@hotmail.com
}

\begin{abstract}
Resumo
O presente estudo teve como objetivo analisar o processo de secagem do tomate, com prévio tratamento osmótico, para verificar a influência de diferentes concentrações de soluto e do tempo de contato do fruto com a solução osmótica. A matéria-prima utilizada foi o tomate Longa Vida. Os agentes osmóticos foram cloreto de sódio e sacarose, nas concentrações de 5 e $10 \%$ e 25 e $35 \%$, respectivamente. O tempo de contato das fatias de tomate com a solução osmótica foi de 1 e 2 horas. Realizou-se a secagem em estufa a $60^{\circ} \mathrm{C}$. Durante esse processo, pesaram-se os tomates a cada 30 minutos (nas primeiras 4 horas) e a cada 60 minutos (no tempo restante de secagem). Os resultados obtidos demonstraram que o pré-tratamento osmótico reduziu a umidade inicial do tomate, o pH e a acidez total titulável. Após oito horas de secagem, obteve-se umidade média de 20,0\%, baixa atividade de água (média de 0,41) e pH menor que 4,5. O rendimento final foi maior em relação ao tomate que não passou pelo tratamento osmótico.
\end{abstract}

Palavras-chave: tomate; desidratação osmótica; secagem; tomate seco.

\section{Introdução}

O tomate (Lycopersicon esculentum Mill.) é considerado um produto agrícola de grande importância, ocupando o primeiro lugar em volume industrializado e o segundo em área cultivada. A cadeia produtiva do tomate processado é provavelmente a mais importante entre todas as hortaliças cultivadas no Brasil. O país é o maior produtor de tomate para processamento industrial e o maior consumidor de produtos derivados de tomate na América do Sul (EMBRAPA, 2006).

Devido à perecibilidade, o mercado de derivados de tomate tem apresentado elevado crescimento e consumo no Brasil, visto que as perdas pós-colheita situam-se entre 25 e $50 \%$. Assim, surgem novos processos de industrialização para reduzir estas perdas. Dentre os derivados de tomate, podem-se destacar extrato, polpa, molhos prontos, catchup e tomate seco (SOUZA, 2002). 
A cultura de consumo do tomate seco teve origem na Itália e apresenta boa aceitação entre os consumidores brasileiros. É um produto desidratado, com textura macia, sendo consumido como tal ou envasado em óleo vegetal, o qual proporciona maior tempo de conservação, oferecendo melhorias no sabor, textura e cor do produto (VENSKE et al., 2004).

A desidratação ou secagem é uma operação unitária utilizada com o objetivo de reduzir a atividade de água dos alimentos. Isto pode significar considerável economia no transporte, no manuseio e na estocagem do produto, bem como, prover um efetivo aumento da vida útil (PEÑA e KIECKBUSCH, 2003).

No entanto, a secagem ocasiona transformações físico-químicas nos alimentos, quase sempre, de forma a prejudicar a qualidade do produto final. Dentre as alterações podem-se citar mudanças na estrutura e na composição da matéria-prima, perda de componentes voláteis e nutrientes, reações de oxidação, colapso da textura total e dificuldade de reidratação (CAMARGO, et al., 2007).

Dentre as diversas metodologias utilizadas para melhorar as características sensoriais de hortaliças desidratadas, a desidratação osmótica, como pré-tratamento à secagem, tem apresentado bons resultados, pois além de reduzir, parcialmente, a atividade de água dos alimentos, diminui o tempo de secagem e melhora a qualidade do produto final (BARONI, 2004).

Este estudo tem por objetivo verificar as alterações de perda de umidade, ganho de sólidos e redução de peso das amostras de tomate com prévio tratamento osmótico, bem como, verificar a umidade e rendimento final dos tomates após secagem.

\section{Material e métodos}

A matéria-prima utilizada foi o tomate Longa Vida, cultivar Débora da espécie industrial Lycopersicum esculentum, selecionando-se os frutos vermelhos por estarem no último grau de maturação (estabelecido visualmente).

\section{Preparo da solução osmótica}

As soluções osmóticas foram preparadas utilizando-se água destilada e os agentes osmóticos, cloreto de sódio e sacarose. As concentrações de cada solução osmótica foram definidas seguindo delineamento experimental conforme descrito na Tabela 1. Foi necessário submeter cada solução a agitação manual para dissolver completamente os solutos. 


\section{Processamento}

\section{Seleção e preparo da matéria-prima}

Para cada ensaio do delineamento experimental, os tomates passaram por seleção conforme o grau de maturação. Em seguida, foram lavados em água corrente e cortados, manualmente, em quatro partes ao longo do eixo, sendo removidas as sementes e o pedúnculo, com posterior pesagem em balança semi-analítica. Para as análises físico-químicas da matéria-prima in natura, foram separados $500 \mathrm{~g}$ de tomate. Outra amostragem de $2 \mathrm{Kg}$ (que não fez parte do delineamento experimental) foi também submetida às etapas de seleção, lavagem, corte, retirada de sementes, lóculo e pedúnculo, bem como, pesagem. Na seqüência, as amostras de tomate foram submetidas à secagem convectiva (secagem teste), em estufa com circulação e renovação de ar, a $60{ }^{\circ} \mathrm{C}$ por dez horas, para comparar o rendimento final, em tomate seco, com os ensaios do delineamento experimental que passaram pelo pré-tratamento osmótico e posterior secagem.

\section{Desidratação osmótica}

Dois quilogramas de tomate foram separados em dois lotes: o primeiro lote, com $500 \mathrm{~g}$, foi colocado em um béquer contendo a solução osmótica na proporção de 3:1 (solução : massa de tomate), em concentração e tempo de contato com a solução pré-definidos, conforme Tabela 1. Após o término do pré-tratamento, os tomates seguiram o enxágüe para a retirada do excesso de soluto (água destilada), drenagem (com auxílio de peneiras), pesagem (em balança semi-analítica) e foram encaminhados para as determinações físico-químicas. O segundo lote com $1500 \mathrm{~g}$ seguiu o mesmo pré-tratamento osmótico. Porém, após osmose, os tomates foram enxaguados, drenados e encaminhados para a secagem convectiva.

Tabela 1 - Delineamento experimental $2^{3}$ com diferentes concentrações de soluto e tempos de imersão para a pré-desidratação e secagem

\begin{tabular}{cccc}
\hline Ensaios & Cloreto de sódio (\%) & Sacarose (\%) & Tempo de imersão (min.) \\
\hline 1 & 5 & 25 & 60 \\
2 & 10 & 25 & 60 \\
3 & 5 & 35 & 60 \\
4 & 10 & 35 & 60 \\
5 & 5 & 25 & 120 \\
6 & 10 & 25 & 120 \\
7 & 5 & 35 & 120 \\
8 & 10 & 35 & 120 \\
\hline
\end{tabular}




\section{Secagem}

Realizada em estufa convectiva (Marconi MA-035/5), com circulação e renovação de ar, a $60{ }^{\circ} \mathrm{C}$. Para esta etapa do processamento, foi utilizado o segundo lote de tomates, já prédesidratados. Os pedaços de tomate foram acondicionados, com a pele para baixo, em formas de alumínio forradas com papel vegetal (as formas com o papel foram previamente pesadas para obter o peso real dos tomates em cada pesagem). Nas primeiras quatro horas de secagem, foram realizadas pesagens a cada 30 minutos e após quatro horas, procederam-se pesagens a cada uma hora, até completarem-se oito horas de secagem. Os tomates secos obtidos foram resfriados a temperatura ambiente, acondicionados em embalagens plásticas e armazenados sob refrigeração. Em todos os ensaios foi realizada a medição diária da umidade relativa do ar, referente ao ambiente de secagem, com o auxílio de um psicrômetro e posterior verificação em carta psicrométrica.

\section{Análises físico-químicas}

Para os tomates in natura e pré-desidratados osmoticamente, foram feitas análises de $\mathrm{pH}$ (com potenciômetro Hanna Instruments, modelo HI 8424), sólidos solúveis ( ${ }^{\circ}$ Brix - refratômetro Atago, modelo $\mathrm{N}-1 \alpha)$, umidade em base úmida $\left(\mathrm{U}_{\mathrm{bu}}\right)$ em estufa a $105{ }^{\circ} \mathrm{C}$ e acidez total titulável (expressa em \% m/m de ácido cítrico) (IAL, 1985). Para as amostras de tomate seco, foram feitas as mesmas determinações físico-químicas, incluindo ainda a umidade em base seca $\left(\mathrm{U}_{\mathrm{bs}}\right)$ e atividade de água (aw), medida no equipamento Decagon - Aqualab.

Todas as determinações físico-químicas foram feitas em triplicata.

\section{Determinação de variáveis}

De acordo com Levi et al. (1983) apud Souza (2002), para as amostras de tomate prédesidratadas osmoticamente, calcularam-se as variáveis Redução de Peso (RP), Ganho de Sólidos (GS) e Perda de Umidade (PU). Já para as amostras de tomate seco determinaram-se as variáveis RP e PU.

\section{Resultados e discussão}

Na Tabela 2 são apresentados os resultados das análises físico-químicas de caracterização do tomate in natura, para cada ensaio correspondente ao delineamento experimental $2^{3}$.

Os resultados das determinações físico-químicas do tomate in natura estão em concordância com os valores especificados na literatura (SOUZA, 2002; MIGUEL et al., 2007). 
Tabela 2 - Caracterização físico-química do tomate in natura antes da desidratação osmótica

\begin{tabular}{ccccc}
\hline Ensaios & $\mathbf{p H}$ & ${ }^{\circ} \mathbf{B r i x}$ & Acidez titulável $(\boldsymbol{\%} \mathbf{~ m} / \mathbf{m})$ & Umidade $(\%)$ \\
\hline 1 & 4,10 & 4,00 & 0,41 & 93,10 \\
2 & 3,95 & 4,00 & 0,36 & 94,30 \\
3 & 4,35 & 4,00 & 0,36 & 95,20 \\
4 & 4,30 & 5,50 & 0,34 & 93,30 \\
5 & 4,35 & 5,40 & 0,37 & 92,50 \\
6 & 4,30 & 5,00 & 0,38 & 91,50 \\
7 & 4,20 & 4,40 & 0,33 & 94,40 \\
8 & 4,10 & 4,50 & 0,42 & 89,20 \\
\hline Intervalos & $3,95-4,35$ & $4,00-5,50$ & $0,33-0,42$ & $89,20-95,20$ \\
Média amostral & 4,20 & 4,60 & 0,37 & 92,90 \\
$*$ Desvio padrão & 0,14 & 0,62 & 0,03 & 1,91 \\
$* *$ CV $(\%)$ & 3,33 & 13,48 & 8,10 & 2,06 \\
\hline
\end{tabular}

*Desvio padrão amostral: $s=\left(\sum\left(x_{i}-\bar{x}\right)^{2} / n-1\right)^{1 / 2}$, somatória dos desvios em relação à média amostral, elevado ao quadrado, dividido pelo número de amostras menos um (CZELUSNIAKI et al., 2003).

**CV: Coeficiente de variação amostral: (Desvio padrão amostral / Média amostral) x 100 (CZELUSNIAKI et al., 2003).

A Tabela 3 apresenta os resultados das análises físico-químicas para as amostras de tomate após pré-tratamento osmótico, onde cada ensaio refere-se ao delineamento experimental $2^{3}$.

Tabela 3 - Caracterização físico-química dos tomates após desidratação osmótica.

\begin{tabular}{ccccc}
\hline Ensaios & $\mathbf{p H}$ & ${ }^{\circ}$ Brix & Acidez titulável $(\% \mathbf{~ m} / \mathbf{m})$ & Umidade $(\%)$ \\
\hline 1 & 4,05 & 7,00 & 0,32 & 91,90 \\
2 & 4,11 & 6,00 & 0,28 & 92,70 \\
3 & 4,29 & 6,00 & 0,28 & 93,90 \\
4 & 4,19 & 7,80 & 0,27 & 91,60 \\
5 & 4,19 & 8,30 & 0,29 & 90,80 \\
6 & 4,13 & 8,00 & 0,30 & 89,70 \\
7 & 3,90 & 6,70 & 0,26 & 92,80 \\
8 & 3,82 & 13,50 & 0,34 & 86,30 \\
\hline Intervalos & $3,82-4,29$ & $6,00-13,50$ & $0,26-0,34$ & $86,30-93,90$ \\
Média amostral & 4,09 & 7,91 & 0,29 & 91,21 \\
*Desvio padrão & 0,16 & 2,42 & 0,02 & 2,37 \\
**CV $(\%)$ & 3,91 & 30,60 & 6,90 & 2,60 \\
\hline *Desvio padrão amostral: & $s=\left(\sum\left(x_{i}-\bar{x}\right)^{2} / n-1\right)^{1 / 2}$, somatória dos desvios em relação à média amostral, elevado ao quadrado, \\
dividido pelo número de amostras menos um. (CZELUSNIAKI et al., 2003). &
\end{tabular}

Conforme se observa, na Tabela 3, o resultado da média amostral da umidade diminuiu em relação à média amostral do tomate in natura (Tabela 2). Isto era esperado, pois um dos objetivos 
do pré-tratamento osmótico é reduzir a umidade inicial do alimento. Além disso, houve incorporação de sólidos solúveis no tomate, justificando o aumento nos valores obtidos em ${ }^{\circ}$ Brix.

Os valores médios referentes à acidez total titulável revelaram uma diminuição após o prétratamento. Conforme Souza (2002), as substâncias solúveis que constituem o alimento podem migrar para a solução osmótica e ocasionar uma redução quantitativa, o que explica os resultados obtidos.

$\mathrm{O}$ pH também apresentou redução após desidratação osmótica. Isso acontece porque o tomate incorpora solutos, principalmente o cloreto de sódio, que faz aumentar a difusividade, com maior perda de água, tornando o alimento com maior teor de sólidos concentrados.

A Tabela 4 apresenta os valores das variáveis Redução de Peso, Ganho de Sólidos e Perda de Umidade, após a desidratação osmótica.

Tabela 4 - Resultados de PU, GS e RP, dos ensaios do delineamento experimental $2^{3}$, após desidratação osmótica.

\begin{tabular}{cccc}
\hline Ensaios & PU $(\%)$ & GS $(\%)$ & RP $(\%)$ \\
\hline 1 & 40,40 & $\mathbf{0 , 0 1 *}$ & 42,70 \\
2 & 40,30 & 0,50 & 41,70 \\
3 & 40,60 & 0,50 & 41,90 \\
4 & 38,90 & 0,90 & 40,70 \\
5 & 41,10 & 0,70 & 43,30 \\
6 & 41,30 & 0,50 & 44,00 \\
7 & 44,90 & 0,80 & 46,70 \\
8 & 50,00 & 1,60 & 54,70 \\
\hline *Valor discordante em relação aos demais ensaios do delineamento experimental.
\end{tabular}

A determinação das variáveis PU e RP resultou em maiores alterações nos últimos quatro ensaios, pois o tempo de contato do tomate com a solução osmótica foi maior (120 minutos) em relação aos ensaios compreendidos entre 1 e 4 (tempo de contato de 60 minutos). De acordo com Souza (2002), durante as duas primeiras horas ocorre a maior transferência de água do alimento para a solução osmótica. Após a desidratação osmótica os ensaios apresentaram aumento percentual de solutos no tomate, comprovados pela determinação de GS. De acordo com Corrêa (2008), o uso de maiores concentrações de sacarose, na solução osmótica, proporciona maior ganho de sólidos, o que explica os resultados obtidos nos ensaios 4, 7 e 8. O ensaio 1 apresentou um valor discordante de GS em relação aos demais, sendo considerado um ensaio anômalo. Isso pode ter ocorrido devido a problemas na homogeneização das amostras, que acabou resultando em um valor que não condiz com o esperado.

$\mathrm{Na}$ Tabela 5 são apresentados os resultados das determinações físico-químicas do tomate após pré-tratamento osmótico e secagem, onde cada ensaio refere-se ao delineamento experimental $2^{3}$. 
Tabela 5 - Caracterização físico-química dos tomates após desidratação osmótica e secagem.

\begin{tabular}{|c|c|c|c|c|c|c|}
\hline Ensaios & $\mathrm{pH}$ & ${ }^{\circ}$ Brix & $\begin{array}{c}\text { Acidez } \\
\text { titulável } \\
(\% \mathrm{~m} / \mathrm{m})\end{array}$ & *aw & $* * \mathrm{U}$ bu $(\%)$ & $* * * \mathrm{U}$ bs $(\%)$ \\
\hline 1 & 4,22 & 50 & 1,78 & 0,34 & 21,93 & 28,09 \\
\hline 2 & 4,02 & 68 & 1,78 & 0,38 & 25,96 & 35,06 \\
\hline 3 & 4,28 & 54 & 1,78 & 0,46 & 33,41 & 50,17 \\
\hline 4 & 4,39 & 73 & 1,85 & 0,54 & 27,05 & 37,08 \\
\hline 5 & 4,30 & 54 & 1,67 & 0,35 & 24,59 & 32,61 \\
\hline 6 & 4,05 & 60 & 2,10 & 0,30 & 19,17 & 23,72 \\
\hline 7 & 3,90 & 70 & 1,74 & 0,29 & 15,13 & 17,83 \\
\hline 8 & 3,96 & 45 & 0,73 & 0,64 & 12,65 & 14,48 \\
\hline Intervalos & $3,90-4,39$ & $45-73$ & $0,73-2,10$ & $0,29-0,64$ & $12,65-33,41$ & $14,48-50,17$ \\
\hline Média amostral & 4,14 & 59,25 & 1,68 & 0,41 & 22,49 & 29,88 \\
\hline ****Desvio padrão & 0,18 & 10,18 & 0,40 & 0,12 & 6,75 & 11,47 \\
\hline$* * * * * \mathrm{CV}(\%)$ & 4,34 & 17,18 & 23,81 & 29,2 & 30,01 & 38,39 \\
\hline \multicolumn{7}{|c|}{$\begin{array}{l}\text { *Atividade de água a temperatura de } 25^{\circ} \mathrm{C} \\
\text { **Umidade em base úmida }\left(\mathrm{U}_{\mathrm{bu}}=\mathrm{Pa} / \mathrm{Pt} \times 100 \text {, onde } P a \text { é o peso da água presente no alimento e } P t \text { é o peso total do alimento). }\right. \\
\text { ***Umidade em base seca }\left(\mathrm{U}_{\mathrm{bs}}=\mathrm{Pa} / \mathrm{Ps} \times 100, \text { onde } P s \text { é o peso da matéria seca). }\right. \\
\text { ****Desvio padrão amostral: } s=\left(\sum\left(x_{i}-\bar{x}\right)^{2} / n-1\right)^{1 / 2} \text {, somatória dos desvios em relação à média amostral, elevado ao } \\
\text { quadrado, dividido pelo número de amostras menos um (CZELUSNIAKI et al., 2003). } \\
\text { *****CV: Coeficiente de variação amostral: (Desvio padrão amostral / Média amostral) x } 100 \text { (CZELUSNIAKI et al., 2003). }\end{array}$} \\
\hline
\end{tabular}

Após a secagem, os solutos incorporados, durante o pré-tratamento osmótico, e as substâncias naturalmente presentes no tomate, concentram-se, o que justifica os valores obtidos neste estudo para acidez e ${ }^{\circ}$ Brix.

A umidade média final, em base úmida, ficou abaixo da maioria dos valores encontrados na literatura, que é entre 25 e $35 \%$, faixa para produtos que apresentam atividade de água intermediária, conforme Camargo (2007).

Para o parâmetro atividade de água (aw), a média amostral foi de 0,41. Esse valor indica que as amostras de todos os ensaios têm baixa propensão à deterioração ou contaminação (GARCIA, 2004). E considera-se o valor de 0,60 como limite mínimo para a multiplicação de grande parte dos microrganismos (FRANCO e LANDGRAF, 2007).

$\mathrm{O}$ pH apresentou pouca alteração, sendo que os valores obtidos após secagem encontraramse abaixo de 4,5, limite máximo para impedir a proliferação de microrganismos patogênicos e inibir os deteriorantes .

As Figuras 1 e 2 ilustram a perda de umidade do tomate durante a secagem, em função do tempo. Os valores de umidade (em base úmida) são expressos em $\mathrm{kg}$ de água/kg de produto. 
Figura 1 - Perda de umidade dos tomates dos ensaios 1 a 4 durante a secagem.

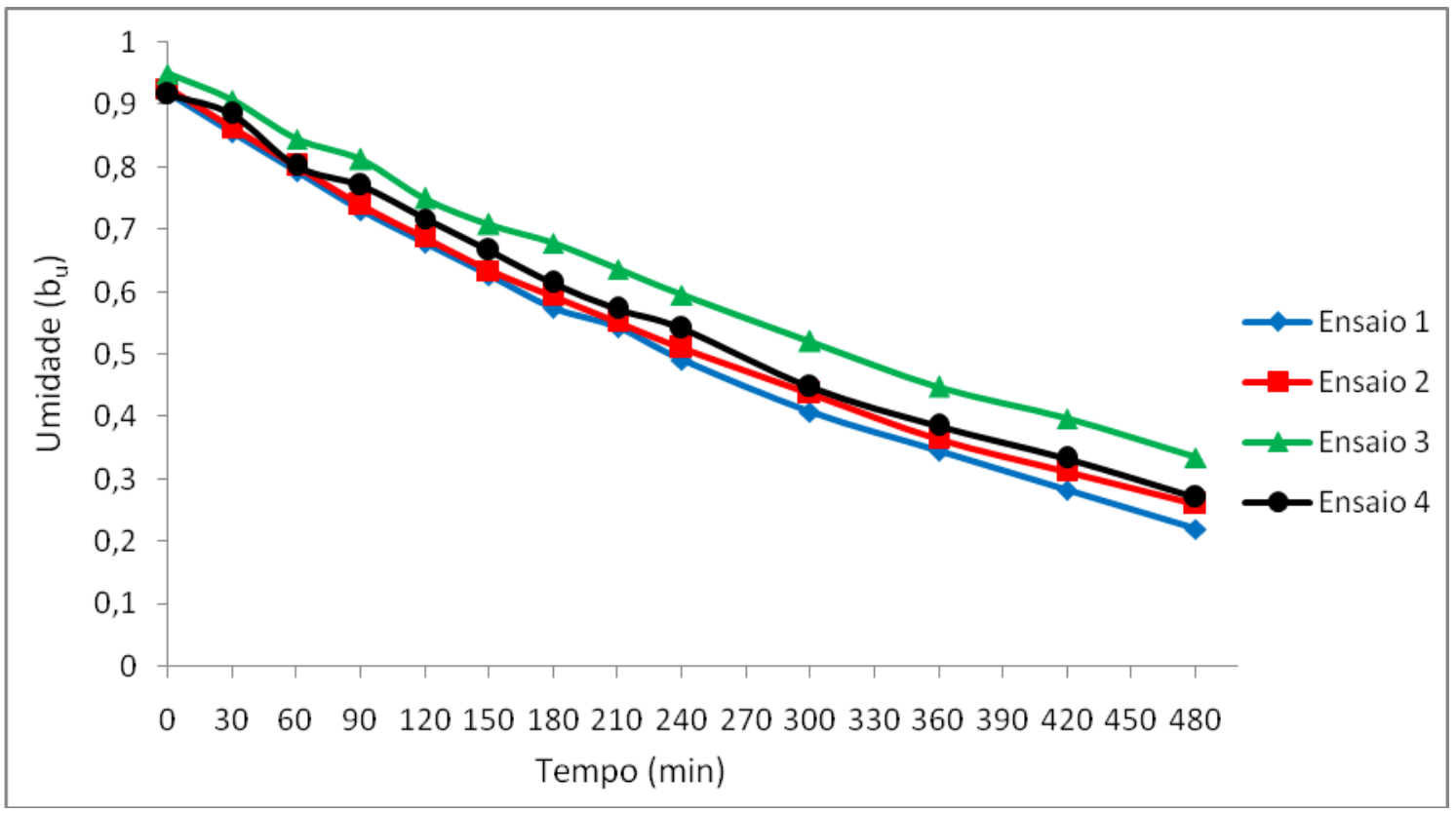

Figura 2 - Perda de umidade dos tomates dos ensaios 5 a 8 durante a secagem.

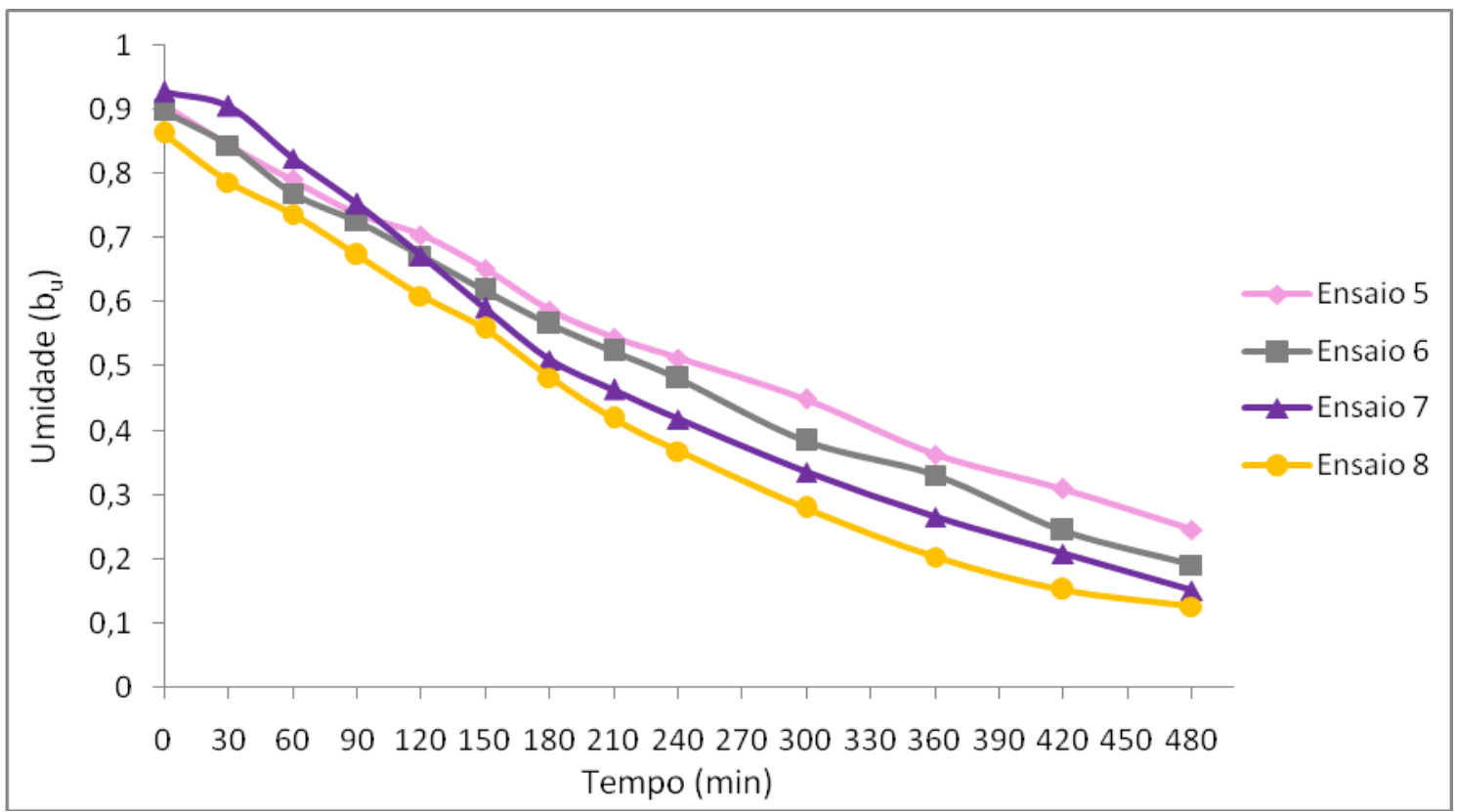

Na Figura 1 são mostrados os ensaios que tiveram tempo de imersão de 60 minutos na solução osmótica. É possível notar que os ensaios 1, 2 e 4 apresentaram umidades próximas e que o ensaio 1 foi o que teve menor umidade final. $\mathrm{O}$ ensaio 3 foi o que mais se diferenciou dos demais; apresentava menor teor de cloreto de sódio, perdeu menos água no pré-tratamento osmótico e consequentemente ficou com teor de umidade maior.

Na Figura 2 são mostrados os ensaios que tiveram tempo de imersão de 120 minutos na solução osmótica. Em comparação com os quatro primeiros ensaios, estes últimos apresentaram menor umidade ao final da secagem. Isso ocorreu porque ficaram imersos na solução osmótica por 
mais tempo e apresentavam menor umidade inicial. Só foi possível este período de secagem (8 horas) porque se realizou uma desidratação osmótica nas amostras, pois o tomate apresenta umidade inicial elevada e o tempo de secagem, normalmente, ultrapassa 10 horas para que o produto final desidratado atinja a umidade de equilíbrio (PEÑA, 1999).

Os resultados da umidade relativa do ar oscilaram entre 60 e $80 \%$, pois o processo de secagem do tomate não foi realizado em um único dia, o que justifica a variação.

Em relação ao rendimento, o ensaio 8 foi o que apresentou menor valor (4\%) porque perdeu muita água para a solução e a incorporação de sólidos não foi suficiente para compensar as perdas. O ensaio 6 foi o que apresentou maior rendimento (7,3\%). A concentração e tempo estabelecidos se mostraram adequados, pois houve um equilíbrio em relação a perda de água e ganho de sólidos fazendo com que o rendimento deste ensaio fosse maior que os demais.

O valor de rendimento obtido no ensaio de secagem teste (que não passou pelo prétratamento osmótico) foi de 5,1\%, assim, pode-se afirmar que a utilização da desidratação osmótica, aliada ao uso de soluções ternárias e ao tempo de contato do alimento com esta solução, melhora o rendimento final, bem como, reduz o tempo de secagem. Esse tempo é menor já que a umidade inicial foi reduzida devido à incorporação de sólidos no tomate durante o tratamento osmótico, resultando assim, em um maior rendimento.

Souza (2002) realizou a pré-desidratação de tomates em solução osmótica composta por 5\% de cloreto de sódio e $35 \%$ de sacarose, com uma temperatura de secagem de $60^{\circ} \mathrm{C}$. Esses valores apresentaram os melhores resultados se comparados com outras proporções de solutos.

Utilizando a concentração osmótica de $15 \%$ de cloreto de sódio e $0,4 \%$ de sacarose, Mata et al. (2003) obtiveram uma remoção de água mais acentuada nos tomates durante a secagem por um período de 10 horas, comparando-se com as outras concentrações de solutos usados no mesmo estudo.

Dessa forma, o pré-tratamento osmótico se mostra como um processo importante na produção de tomate desidratado. A perda de água e a incorporação de sólidos variam em cada caso, mas as vantagens como redução do tempo de secagem, manutenção da boa aparência do produto e maior rendimento econômico, estão sempre presentes.

\section{Conclusão}

Os resultados demonstraram que a utilização do pré-tratamento osmótico auxilia na redução da umidade e de peso das amostras de tomate em, aproximadamente $45 \%$, bem como, aumenta a rentabilidade do produto final, sendo 7,3\% no ensaio que apresentou melhor rendimento. 
Os tomates secos apresentaram umidade, em base úmida, menor que 20,0\%, após 8 (oito) horas de secagem, baixa atividade de água (em média 0,41) e pH menor que 4,5 (média de 4,14), parâmetros importantes para a conservação do produto.

\begin{abstract}
This study aimed to analyze the drying process of tomato, with previous osmotic treatment to verify the influence of different solute concentrations and contact time of the fruit to osmotic solution. The raw material used was the tomato "Longa Vida". The osmotic agents were sodium chloride and sucrose, at concentrations of 5 and $10 \%$ and 25 and 35\% respectively. The contact time of tomato slices with the osmotic solution was 1 and 2 hours. Drying was performed in an oven-drying at $60^{\circ} \mathrm{C}$. During this process, the tomatoes were weighed every 30 minutes (in the first 4 hours) and every 60 minutes (in the remaining drying time). The results show that the pretreatment reduced the initial moisture of the tomatoes, $\mathrm{pH}$ and total acidity. After 8 hours of drying, the moisture score was $20.0 \%$, the water activity was low (average of 0.41) and $\mathrm{pH}$ was lower than 4.5. The final yield was higher than tomatoes that has not pass through the osmotic treatment.
\end{abstract}

Key-words: tomato; osmotic dehydration; drying; dried tomato.

\title{
Referências
}

BARONI, A. F. Propriedades mecânicas, termodinâmicas e de estado de tomate submetido à desidratação osmótica e secagem. 2004. 268 f. Tese (Doutorado em Engenharia de Alimentos) - Programa de Pós-Graduação em Engenharia de Alimentos, Universidade Estadual de Campinas, Campinas.

CAMARGO, G. A.; HAJ-ISA, N.; QUEIROZ, M. R. de. Avaliação da qualidade de tomate seco em conserva. Revista Brasileira de Engenharia Agrícola e Ambiental, Campina Grande, v. 11, n. 5, p. 521-526, 2007.

CORRÊA, J. L. G.; SILVA FILHO, E. D.; BATISTA, M. B.; AROLA, F.; FIOREZE, R. Desidratação osmótica de tomate seguida de secagem. Revista Brasileira de Produtos Agroindustriais, Campina Grande, v. 10, n. 1, p. 35-42, 2008.

CZELUSNIAK, C.; OLIVEIRA, M. C. S.; NOGUEIRA, A.; SILVA, N. C. C.; WOSIACKI, G. Qualidade de maçãs comerciais produzidas no Brasil: aspectos físico-químicos. Brazilian Journal of Food Technology, Campinas, v. 6, n. 1, p. 25-31, jan./jun. 2003.

EMBRAPA. Empresa Brasileira de Pesquisa Agropecuária. Cultivo de Tomate para Industrialização. 2006. Disponível em: <http://sistemasdeproducao.cnptia.embrapa.br/FontesHTML/Tomate/TomateIndustrial_2ed/index. htm>. Acesso em 5 jan. 2011.

FRANCO, B. D. G. M.; LANDGRAF, M. Microbiologia dos Alimentos. 2. ed. Rio de Janeiro: Atheneu, 2007.

GARCIA, D. M. Análise de atividade de água em alimentos armazenados no interior de granjas de integração avícola. 2004. 50 f. Dissertação (Mestrado Ciências Veterinárias) - Programa de Pós-Graduação em Ciências Veterinárias, Universidade Federal do Rio Grande do Sul, Porto Alegre.

IAL - INSTITUTO ADOLFO LUTZ. Normas Analíticas: métodos químicos e físicos para a análise de alimentos. 3 ed., v. 1. São Paulo. 1985.

MATA, M. E. R. M. C.; BRAGA, M. E. D.; KROSS, R. K. Secagem osmótica de tomate: efeito da epiderme. Revista Brasileira de Produtos Agroindustriais, Campina Grande, n. 1, p. 77-84, 2003.

MIGUEL, A. C. A.; DIAS, J. R. P. S.; SPOTO, M. H. F.; RIZZO-BENATO, R. T. Qualidade do tomate 'Débora' minimamente processado armazenado em dois tipos de embalagens. Horticultura Brasileira, Brasília, v. 25, n. 4, p. 582-585, out./dez. 2007. 
PEÑA, L. M. R. Estudo de pré-tratamento para a obtenção de tomates em fatias. 1999. 129 f. Dissertação (Mestrado em Engenharia Química) - Programa de Pós-Graduação em Engenharia Química, Universidade Estadual de Campinas, Campinas.

PEÑA, L. M. R.; KIECKBUSCH, T. G. Influência de condições de secagem na qualidade de fatias de tomate. Brazilian Journal of Food Technology, Campinas, v. 6, n. 114, p. 69-76, jan./jun. 2003.

SOUZA, J. S. Estudo da desidratação de tomates (Lycopersicum esculentum) em pedaços com pré-tratamento osmótico. 2002. 105 f. Dissertação (Mestrado em Engenharia Química) - Programa de Pós-Graduação em Engenharia Química, Universidade Federal do Rio Grande do Norte, Natal.

VENSKE, C.; SANTOS, J.; RAUPP, D. S.; GARDINGO, J. R.; BORSATO, A. V. Influência do grau de maturação nas características sensoriais de tomate seco envasado em óleo. Publicatio UEPG - Ciências Exatas e da Terra, Agrárias e Engenharias, Ponta Grossa, v. 10, n. 3, p. 33-40, 2004.

Submetido em 09 ago 2010; Revisão enviada pelos autores em 10 jan 2011; Aceito para publicação em 30 jun.2011. 